\title{
Estimation of the HIV Incidence and of the Number of People Living With HIV/AIDS in Brazil, 2012
}

\author{
Célia Landmann Szwarcwald ${ }^{1, *}$, Ana Roberta Pati Pascom² and Paulo Roberto de Souza Júnior ${ }^{1}$ \\ ${ }^{1}$ Institute of Communication and Information Science and Technology in Health, Oswaldo Cruz Foundation, Rio de Janeiro, Brazil \\ ${ }^{2}$ Department of STD, AIDS and Viral Hepatitis, Ministry of Health, Brazil
}

\begin{abstract}
Introduction: In this study, statistical techniques were applied to reconstruct the historical HIV infection curve using all available surveillance data sources in Brazil, including AIDS reported cases, HIV incident cases in recent years, and AIDS deaths. Using this model, we estimated the HIV incidence and the number of people living with HIV/ AIDS (PLWHA) in Brazil, 2012.

Methods: To estimate HIV incidence in the period 2005-2012, we used a new method based on a CD4 count depletion model. From SISCEL information, we estimated the time lag between HIV infection and the date of first CD4 count for each treatment-naïve HIV infected case aged 15 years or older. To estimate the HIV incidence in past years, we used an extended back calculation method. Then, we used the back-calculating estimates of HIV incidence from AIDS reported cases together with the estimates of HIV incidence in recent years (2005-2012) to reconstruct the HIV incidence curve, in Brazil. To calculate the total prevalence in the middle of 2012, we used the accumulated incident cases and the total number of deaths up to the middle of year 2012.
\end{abstract}

Results: By midyear 2012, 672959 AIDS cases have been reported, and from those, 336391 were alive. In the middle of 2012, the prevalence was 715003 and the prevalence rate 3.7 per 1000 population. The number of HIV cases infected in 2012 of 47573 represents $6.6 \%$ of the total prevalence, with an incidence rate of 24.5 per 100,000 populations. The number of prevalent cases with no CD4 count in the middle of 2012 was 240333 , or $33.6 \%$ of the total number of PLWHA.

Discussion: Currently, the Ministry of Health adopted the new policy of offering immediate treatment to those diagnosed with HIV and new challenges have to be faced. In this study, we estimated that around 715,000 people live with HIVIAIDS in Brazil, from which one third do not have a CD4 count, and is not benefiting from the new policy. As patients who belatedly starting therapy have lower survival, consume more resources, and reduce the chances of therapy success, policies to eliminate structural barriers to HIV testing are essential in Brazil.

Keywords: HIV incidence; HIV prevalence; CD4 count; AIDS deaths; Estimation methods; Brazil

\section{Introduction}

In the early years of AIDS, it was believed that AIDS incidence surveillance together with estimates of time from HIV infection to AIDS would be sufficient for understanding the dynamics of the epidemic spread. Back calculation methods with assumptions about the incubation period distribution have been used in many countries to provide estimates of HIV incidence from AIDS surveillance data [1-5]. The introduction of highly anti-retroviral therapy (HAART) in 1996, however, has shown an important effect on the AIDS incubation period, making necessary to supplement AIDS incidence data with other sources of information [6].

In the last two decades, several countries have adopted the prevalence of HIV as an important indicator of surveillance [7-9]. Models fitted to sentinel surveillance data on antenatal care services and population-based HIV testing surveys have been frequently used for monitoring HIV prevalence [10-11]. Among sub-Saharan countries, Demographic and Health Surveys have been continuously applied and have become central for deriving estimates of national HIV prevalence $[12,13]$.

In Brazil, the characterization of the AIDS epidemic has been conducted by the Ministry of Health using the Information System of AIDS reported cases (SINAN/AIDS). In the 1990s, HIV surveillance was extensively based on monitoring the number of new AIDS reported cases [14-16]. After 2000, besides trends of AIDS incidence by sex, age and exposure category [17], the HIV prevalence has been estimated periodically using national probabilistic samples of pregnant women at the time of hospitalization for delivery $[8,18]$. The estimate has been used to generalize HIV prevalence for the Brazilian population and to monitor its trend. Lately, difficulties in estimating the male-female ratio limited the use of this method to estimate HIV prevalence in the general population.

Behavioral surveys among Brazilian army conscripts have also been used to monitor HIV infection among young men associated with risk behaviors [19]. Among most at risk populations, RDS studies have been carried out in 10 Brazilian cities to find the HIV prevalence and associated risk factors $[20,21]$.

However, in the context of expansion of antiretroviral treatment to HIV-infected individuals and increased survival [22,23], it is

*Corresponding author: Célia Landmann Szwarcwald, Institute of Communication and Information Science and Technology in Health, Oswaldo Cruz Foundation, Rio de Janeiro, Brazil, Tel: 55-21-38653239; E-mail: celia_Is@hotmail.com

Received January 24, 2015; Accepted February 12, 2015; Published February 21,2015

Citation: Szwarcwald CL, Pascom ARP, de Souza Júnior PR (2015) Estimation of the HIV Incidence and of the Number of People Living With HIVIAIDS in Brazil, 2012. J AIDS Clin Res 6: 430. doi:10.4172/2155-6113.1000430

Copyright: (c) 2015 Bestawros M, et al. This is an open-access article distributed under the terms of the Creative Commons Attribution License, which permits unrestricted use, distribution, and reproduction in any medium, provided the original author and source are credited. 
increasingly difficult to interpret HIV prevalence data, making essential to have HIV incidence estimates for identifying sub-populations and geographical areas most at risk for HIV infection. Estimates of HIV incidence are increasingly being incorporated into HIV/AIDS surveillance activities in many countries [24-27].

As the HIV/AIDS epidemic enters its fourth decade, Brazil has collected a long time series of AIDS surveillance data, while the AIDSspecific mortality has been substantially reduced by the widespread use of antiretroviral treatment [22]. In this study, statistical techniques were applied to reconstruct the historical HIV infection curve using all available surveillance data sources in Brazil, including AIDS reported cases, HIV incident cases in recent years, and AIDS deaths. Using this model, we estimated the number of people living with HIV/AIDS in Brazil, 2012, making possible to evaluate the earliest phases of the HIV treatment cascade [28].

\section{Methods}

\section{Sources of information}

The main source of information was the Brazilian Information System of AIDS reported cases (SINAN/AIDS), which contains information of AIDS cases from 1980 to the present. From year 2000 on, the SINAN/AIDS has been linked to the Mortality Information System on a routine basis to capture AIDS deaths and undiagnosed AIDS cases.

In addition to relying on information provided by the AIDS reported cases in SINAN/AIDS and AIDS deaths from the Mortality Information System (SIM), the HIV/AIDS surveillance in Brazil has two specific information systems which are managed centrally by technical staff of the Brazilian Department of AIDS and Sexually Transmitted Diseases: the Laboratory Tests Control System (SISCEL) created to monitor CD4 counts and HIV viral load, and the System of Medication Logistic Control (SICLOM) developed to control the distribution and management of antiretroviral drugs, as well as for obtaining clinical and laboratory information from AIDS patients under use of different treatment regimens.

After year 2002, the SINAN/AIDS has been routinely linked to SISCEL and to SICLOM based on a probabilistic procedure [29] to capture AIDS cases not reported to SINAN/AIDS. In the present study, we analyzed the SINAN/AIDS Information System and the SISCEL database after removing patients' identifiers. The project was approved by the Ethics Committee of the Oswaldo Cruz Foundation, Ministry of Health, Brazil.

\section{HIV incidence estimation}

Estimation in recent years: First, to estimate HIV incidence in the period 2005-2012, we used a new method based on the first CD4 count after HIV diagnosis. Using a statistical model proposed in an earlier study that relates the first CD4 count to time of HIV infection [30], we estimated the time lag between HIV infection and the date of first CD4 count for each treatment-naïve HIV infected case aged 15 years or older informed to the Laboratory Information System (SISCEL).

The CD4 depletion model relates the square root of the first CD4 count $\left(\mathrm{CD4}_{1}\right)$ to time of infection through a linear mixed model:

$$
\sqrt{C D 4_{1}}=\mathbf{b}_{0}+\mathbf{b}_{1} t
$$

where $t$ is the time from HIV infection to date of first CD4 count, and the slope $\left(\mathbf{b}_{\mathbf{1}}\right)$ and the intercept $\left(\mathbf{b}_{\mathbf{0}}\right)$ are random variables following normal distributions. The mean values and the standard deviations of the slope and the intercept were estimated separately for combinations of sex, quartile of age at infection, and risk group [30].

To use the model in Brazil, as SISCEL does not have information about risk group, we adapted the CD4 depletion model and calculated the intercept and the slope by sex and age using the distribution of risk group among AIDS cases in Brazil to weight the parameters $\mathbf{b}_{\mathbf{0}}$ and $\mathbf{b}_{1}$ within each sex and age group. For each treatment-naïve HIV infected case reported to SISCEL, we used equation (1) to estimate the time lag between infection and the date of first CD4 count based on the simulated values of the linear model coefficients and the first CD4 count of the individual. To account for cases tested in the private sector, we weighted the SISCEL database with weights inversely proportional to the coverage of private health insurance by geographical area of residence [31].

HIV incidence was estimated as a weighted sum of cases reported to SISCEL in the same year of infection, one year after infection, and so on through 20 years after infection. Mathematically, let $\mathbf{x}_{\mathbf{k}}$ be HIV incidence in year $\mathbf{k}$ and $\mathbf{y}_{\mathbf{k}}$ the number of cases reported to SISCEL in year $\mathbf{k}$. Then,

$$
\text { (2) } \mathrm{x}_{\mathrm{k}}=\mathrm{p}_{0 \mathrm{k}} \mathrm{y}_{\mathrm{k}}+\mathrm{p}_{1 \mathrm{k}+1} \mathrm{y}_{\mathrm{k}+1}+\mathrm{p}_{2 \mathrm{k}+2} \mathrm{y}_{\mathrm{k}+2}+\ldots . .+\mathrm{p}_{20 \mathrm{k}+20} \mathrm{y}_{\mathrm{k}+20},
$$

where $\mathbf{p}_{\mathbf{i k}+\mathbf{i}}$ is the probability the case is reported to SISCEL $\mathbf{i}=\mathbf{0}, \mathbf{1}, \ldots \mathbf{2 0}$ years after infection in year $\mathbf{k}$ for $\mathbf{k}=2005, \ldots ., 2012$. Annual numbers of cases reported to SISCEL in years 2013-2032 (denoted as $\mathbf{y}_{2013, \ldots . .,} \mathbf{y}_{2032}$ ) were estimated through a linear regression model based on annual numbers of cases reported to SISCEL in the period 2005-2012 and the probability values of $\mathbf{p}_{0 \mathrm{k}}, \mathbf{p}_{1 \mathrm{k}+1, \ldots . .} \mathbf{p}_{20 \mathrm{k}+20}$ were estimated based on the distribution of $\mathbf{t}$ (time between HIV infection and first CD4 count) in the period 2005-2012.

Finally, to obtain total HIV incidence for the Brazilian population in the period 2005-2012, we used two correction factors. Based on the proportion of SISCEL cases 15 years and over (91\%) in 2012, we used a correction factor of $\mathbf{1 . 1}$ to account for HIV incident cases aged less than 15 years old. The second correction factor, 1.02, was used to account for HIV infected cases that died before diagnosis, based on the proportion of reported AIDS cases with diagnosis only at death, that is, have never been linked to care.

Estimation in past years: To estimate the HIV incidence in past years, we used an extended back calculation method. The source of information was the SINAN/AIDS Information System, which contains information of HIV/AIDS cases from 1980 to the present. To estimate the time between HIV infection and AIDS, we applied again the CD4 depletion model (Equation 1).

For all reported AIDS cases aged 15 years and over, we calculated the mean and the standard deviation of model 1 parameters according to sex, quartiles of age at AIDS diagnosis, and risk group. Then, for each AIDS reported case, we simulated the values of the intercept and the slope based on normal distribution functions.

For AIDS cases reported after 2002 with information of the first CD4 count, we calculated the time lag between HIV infection and AIDS based on the square root of first CD4 count (equation 1). For all other SINAN cases aged 15 years and over, we estimated the time of infection to AIDS based on the simulated values of model 1 parameters and the CD4 count of 200 cells/ $\mu \mathrm{L}$, the primary diagnostic criterion for an AIDS diagnosis. With this approach, we estimated the HIV incidence up to 1993.

For AIDS reported cases due to vertical transmission, the date of 
HIV infection was the date of birth. For AIDS reported cases aged less than 15 years old and not due to vertical transmission, the year of HIV infection was considered the year of the $12^{\text {th }}$ birthday.

Then, we used the back-calculating estimates of HIV incidence from AIDS reported cases together with the estimates of HIV incidence in recent years (2005-2012) to reconstruct the HIV incidence curve, in Brazil. A regression model was used to estimate the missing intermediate values, from 1994 to 2004 . We used time (year of infection) and logarithm of time as the independent variables and the estimated HIV incidence in 1990-93 and 2005-2012 as the response variable.

HIV prevalence estimation: To calculate the total prevalence in the middle of 2012, we used the accumulated incident cases and the total number of deaths up to the middle of year 2012. Although AIDS mortality data is available since the beginning of the epidemic in Brazil, more accurate AIDS mortality data are provided from 2000 on, after linkage of SINAN and the Mortality Information System. Therefore, to calculate the total number of deaths, we considered the following assumptions:

i) In the period 1980-1994, we assumed that all AIDS cases reported in this period died before 2012 and estimated the correction factor (1.79) as the ratio between the AIDS reported cases and the number of reported deaths;

ii) In the period 1995-1999, the number of deaths was corrected by 1.44 , accounting for deaths from other causes, ill defined causes and underreporting of deaths [32];

iii) In the period 2000-2012, after linkage of SINAN and the Mortality Information System, the number of deaths was corrected by a factor that varied from 1.12 (2000) to 1.06 (2012) accounting only for ill defined causes and underreporting of deaths.

The number of people living with HIV/AIDS in the middle of 2012 was calculated by subtracting the total number of deaths from the cumulative HIV incidence up to the middle of year 2012.

Number of HIV cases with no CD4 count: Since notification of HIV infection become compulsory only in June, 2014 in Brazil, SISCEL is the unique information system to identify diagnosed HIV infected people. In this study, we estimated the number of PLWHA who do not have CD4 count after 20 years of infection.

To estimate the number of PLWHA with no CD4 count in 2012, we used the distribution of the time lag between HIV infection and first CD4 count. The proportions of delay of 20 years, 19 years,...., 1 year after HIV infection were applied to HIV incident cases between 1992 and 2012. The cumulative sum of HIV infected cases from 1992 to midyear 2012 with no CD4 count provided the estimate.

\section{Results}

In Table 1, we exemplify the estimation of HIV incidence in year 2012. After the use of the CD4 depletion model (1), we estimated the distribution of the time lag between HIV infection and the first CD4 count in the period 2005-2012 (column 2). The predicted values of the probability the case infected in 2012 is reported to SISCEL in 2012 to 2032 are presented in column 4 . The predicted values of the numbers of cases reported to SISCEL from 2012 to 2032 are in column 5. The predicted SISCEL cases multiplied by the predicted probabilities are in column 6. Application of equation 2 provides HIV incidence among people aged 15 years and older, and multiplication by the correction factors results in the total HIV incidence in 2012. We note that the

\begin{tabular}{|c|c|c|c|c|c|}
\hline t (years) & $\begin{array}{l}\text { Distribution } \\
\text { of } t \text { 2005-2012 }\end{array}$ & year & $\mathbf{P}_{\mathrm{t}, 2012}$ & $\mathbf{y}$ & $\mathbf{P}_{\mathrm{t}, 2012^{*}} \mathbf{y}$ \\
\hline$<1$ & 0.316 & 2012 & 0.339 & 44348 & 15052 \\
\hline$\geq 1$ and $<2$ & 0.052 & 2013 & 0.051 & 44986 & 2294 \\
\hline$\geq 2$ and $<3$ & 0.052 & 2014 & 0.051 & 45625 & 2327 \\
\hline$\geq 3$ and $<4$ & 0.051 & 2015 & 0.051 & 46263 & 2359 \\
\hline$\geq 4$ and $<5$ & 0.051 & 2016 & 0.050 & 46901 & 2345 \\
\hline$\geq 5$ and $<6$ & 0.048 & 2017 & 0.048 & 47540 & 2282 \\
\hline$\geq 6$ and $<7$ & 0.045 & 2018 & 0.045 & 48178 & 2168 \\
\hline$\geq 7$ and $<8$ & 0.041 & 2019 & 0.040 & 48816 & 1953 \\
\hline$\geq 8$ and $<9$ & 0.037 & 2020 & 0.390 & 49455 & 1929 \\
\hline$\geq 9$ and $<10$ & 0.035 & 2021 & 0.035 & 50093 & 1753 \\
\hline$\geq 10$ and $<11$ & 0.033 & 2022 & 0.031 & 50732 & 1573 \\
\hline$\geq 11$ and $<12$ & 0.031 & 2023 & 0.027 & 51370 & 1387 \\
\hline$\geq 12$ and $<13$ & 0.030 & 2024 & 0.023 & 52008 & 1196 \\
\hline$\geq 13$ and $<14$ & 0.028 & 2025 & 0.020 & 52647 & 1053 \\
\hline$\geq 14$ and $<15$ & 0.026 & 2026 & 0.014 & 53285 & 746 \\
\hline$\geq 15$ and $<16$ & 0.025 & 2027 & 0.010 & 53923 & 539 \\
\hline$\geq 16$ and $<17$ & 0.023 & 2028 & 0.008 & 54562 & 436 \\
\hline$\geq 17$ and $<18$ & 0.019 & 2029 & 0.006 & 55200 & 331 \\
\hline$\geq 18$ and $<19$ & 0.015 & 2030 & 0.005 & 55838 & 279 \\
\hline$\geq 19$ and $<20$ & 0.012 & 2031 & 0.004 & 56477 & 226 \\
\hline$\geq 20$ & 0.030 & 2032 & 0.003 & 57115 & 172 \\
\hline \multicolumn{5}{|c|}{$\begin{array}{l}\text { Estimated HIV Incidence among individuals aged } 15 \text { years and } \\
\text { over }\end{array}$} & 42401 \\
\hline \multicolumn{5}{|c|}{ Estimated total HIV Incidence } & 47573 \\
\hline
\end{tabular}

Table 1: Distribution of the time lag (t) between HIV infection and the first CD4 count in the period 2005-2012, predicted proportions ( $\left.\mathbf{P}_{\mathbf{1 2 0 1 2}}\right)$ of cases receiving a CD4 test within estimated ranges of time since infection in 2012, predicted number of SISCEL cases (y) by year, and estimated HIV incidence. Brazil, 2012.

numbers of SISCEL reported cases in years farther out by more than 10 years have a very limited effect on the incidence estimate because only a very small proportion of cases reported in those years will actually result from infections in 2012.

In Table 2, we presented the number of AIDS reported cases, the number of informed deaths, and the corrected number of deaths. By midyear 2012, 672959 AIDS cases have been reported, and from those, 336391 were alive.

Results of the extended back-calculating procedure to estimate the HIV incidence in past years (1980-1994) based on AIDS reported cases (SINAN) are presented in Table 3. In the same table, we show the HIV incidence estimates in recent years (2005-2012), estimated on the basis of the first CD4 count among treatment naive cases informed to SISCEL.

A regression model was used to predict the HIV incidence between 1993 and 2004. The two curves fit together very well and the multiple correlation coefficient was very close to 1 (Figure 1).

To find the number of people living with HIV/AIDS by midyear 2012 (prevalence), we accumulated the incident cases and subtracted the estimated number of deaths. In the middle of 2012, the prevalence was 715003 and the prevalence rate 3.7 per 1000 populations. The number of HIV cases infected in 2012 of 47573 represents $6.6 \%$ of the prevalence, with an incidence rate of 24.5 per 100,000 populations.

In Table 4, we show the cumulative distribution of the time lag between HIV infection and first CD4 count in the period 2005-12. After multiplication of the proportions of cases without first CD4 count by the number of HIV incident cases between 1992 and 2012, the 
Page 4 of 7

\begin{tabular}{|c|c|c|c|c|}
\hline $\begin{array}{c}\text { Year of AIDS } \\
\text { diagnosis }\end{array}$ & $\begin{array}{c}\text { Number of } \\
\text { AIDS reported } \\
\text { cases }\end{array}$ & $\begin{array}{l}\text { Reported } \\
\text { number of } \\
\text { deaths }\end{array}$ & $\begin{array}{l}\text { Corrected } \\
\text { number of } \\
\text { deaths }\end{array}$ & $\begin{array}{l}\text { Number of } \\
\text { alive AIDS } \\
\text { cases }\end{array}$ \\
\hline 1980 & 1 & 1 & 1 & 0 \\
\hline 1981 & 0 & 0 & 0 & 0 \\
\hline 1982 & 14 & 3 & 14 & 0 \\
\hline 1983 & 41 & 12 & 41 & 0 \\
\hline 1984 & 134 & 70 & 134 & 0 \\
\hline 1985 & 523 & 271 & 523 & 0 \\
\hline 1986 & 1107 & 557 & 1107 & 0 \\
\hline 1987 & 2672 & 1291 & 2672 & 0 \\
\hline 1988 & 4321 & 2365 & 4321 & 0 \\
\hline 1989 & 5976 & 3625 & 5976 & 0 \\
\hline 1990 & 8574 & 5077 & 8574 & 0 \\
\hline 1991 & 11401 & 6246 & 11401 & 0 \\
\hline 1992 & 14095 & 7095 & 14095 & 0 \\
\hline 1993 & 16281 & 9182 & 16281 & 0 \\
\hline 1994 & 17822 & 10539 & 17822 & 0 \\
\hline 1995 & 20539 & 13162 & 18953 & 1586 \\
\hline 1996 & 23314 & 12284 & 17689 & 5625 \\
\hline 1997 & 25552 & 9602 & 13827 & 11725 \\
\hline 1998 & 28351 & 9440 & 13594 & 14757 \\
\hline 1999 & 25919 & 11271 & 16230 & 9689 \\
\hline 2000 & 28685 & 11068 & 12406 & 16279 \\
\hline 2001 & 29526 & 11274 & 12624 & 16902 \\
\hline 2002 & 36583 & 12486 & 13917 & 22666 \\
\hline 2003 & 35743 & 12768 & 14223 & 21520 \\
\hline 2004 & 35347 & 12471 & 13871 & 21476 \\
\hline 2005 & 35755 & 12353 & 13567 & 22188 \\
\hline 2006 & 35494 & 12665 & 13739 & 21755 \\
\hline 2007 & 39465 & 13074 & 14107 & 25358 \\
\hline 2008 & 41571 & 13551 & 14581 & 26990 \\
\hline 2009 & 41477 & 13725 & 14751 & 26726 \\
\hline 2010 & 41476 & 13337 & 14312 & 27164 \\
\hline 2011 & 43778 & 13256 & 14170 & 29608 \\
\hline 2012 & 42844 & 13232 & 14089 & 28755 \\
\hline $\begin{array}{c}\text { Total number } \\
\text { by midyear } \\
2012\end{array}$ & 672959 & 260737 & 336568 & 336391 \\
\hline
\end{tabular}

Table 2: Number of AIDS reported cases, corrected number of deaths, and number of alive AIDS cases in midyear 2012. Brazil, 1980-2012.

number of prevalent cases without a CD4 count in the midyear of 2012 was 240333 , or $33.3 \%$ of the total number of PLWHA.

\section{Discussion}

In 1996, a landmark law made ARV drugs available to AIDS patients at no cost through the public health care system (SUS). The availability of free universal antiretroviral treatment has resulted in a dramatic improvement in patient survival and a significant decrease in AIDS hospitalizations. Between 1982 and 1989, the average survival of adult AIDS cases was estimated to be 5.1 months; by 1995, survival for adult AIDS cases increased to18 months, and by 1996, to 58 months [33]. Survival analysis in years $1998-99$ indicated that $60 \%$ of the patients survived at least 108 months after AIDS diagnosis [22]. Important evidence of survival increase among children has been documented as well [34].

Currently, the Ministry of Health adopted the new policy of offering treatment to those diagnosed with HIV, the "test and treat"

\begin{tabular}{|c|c|c|c|c|}
\hline $\begin{array}{l}\text { Year of AIDS } \\
\text { diagnosis }\end{array}$ & $\begin{array}{c}\text { Based on } \\
\text { AIDS reported } \\
\text { cases }\end{array}$ & $\begin{array}{l}\text { Based on } 1^{\text {st }} \\
\text { CD4 count }\end{array}$ & $\begin{array}{c}\text { Predicted HIV } \\
\text { incidence }\end{array}$ & $\begin{array}{c}\text { Estimated HIV } \\
\text { incidence }\end{array}$ \\
\hline 1967 & 1 & & & 1 \\
\hline 1968 & 2 & & & 2 \\
\hline 1969 & 4 & & & 4 \\
\hline 1970 & 10 & & & 10 \\
\hline 1971 & 22 & & & 22 \\
\hline 1972 & 28 & & & 28 \\
\hline 1973 & 53 & & & 53 \\
\hline 1974 & 107 & & & 107 \\
\hline 1975 & 201 & & & 201 \\
\hline 1976 & 418 & & & 418 \\
\hline 1977 & 874 & & & 874 \\
\hline 1978 & 1733 & & & 1733 \\
\hline 1979 & 3039 & & & 3039 \\
\hline 1980 & 4694 & & & 4694 \\
\hline 1981 & 6793 & & & 6793 \\
\hline 1982 & 9177 & & & 9177 \\
\hline 1983 & 12193 & & & 12193 \\
\hline 1984 & 15138 & & & 15138 \\
\hline 1985 & 17683 & & & 17683 \\
\hline 1986 & 19960 & & & 19960 \\
\hline 1987 & 22402 & & & 22402 \\
\hline 1988 & 24880 & & & 24880 \\
\hline 1989 & 26772 & & & 26772 \\
\hline 1990 & 28538 & & & 28538 \\
\hline 1991 & 30177 & & & 30177 \\
\hline 1992 & 31646 & & & 31646 \\
\hline 1993 & 32723 & & & 32723 \\
\hline 1994 & & & 33934 & 33934 \\
\hline 1995 & & & 34931 & 34931 \\
\hline 1996 & & & 35890 & 35890 \\
\hline 1997 & & & 36813 & 36813 \\
\hline 1998 & & & 37703 & 37703 \\
\hline 1999 & & & 38562 & 38562 \\
\hline 2000 & & & 39392 & 39392 \\
\hline 2001 & & & 40194 & 40194 \\
\hline 2002 & & & 40970 & 40970 \\
\hline 2003 & & & 41722 & 41722 \\
\hline 2004 & & & 42450 & 42450 \\
\hline 2005 & & 43331 & & 43331 \\
\hline 2006 & & 43927 & & 43927 \\
\hline 2007 & & 44528 & & 44528 \\
\hline 2008 & & 45130 & & 45130 \\
\hline 2009 & & 45736 & & 45736 \\
\hline 2010 & & 46346 & & 46346 \\
\hline 2011 & & 46957 & & 46957 \\
\hline 2012 & & 47573 & & 47573 \\
\hline \multicolumn{4}{|c|}{ Total by midyear 2012} & 1051571 \\
\hline
\end{tabular}

Table 3: Estimated HIV incidence. Brazil, 1967-2012.

policy, and new challenges have to be faced [35]. There is a growing interest in the potential impact of wide and immediate treatment policy that could substantially reduce morbidity and mortality from HIV, and secondarily HIV transmission at the population level [36]. In the new scenario, the HIV treatment continuum, or "cascade of HIV care" has become a relevant HIV/AIDS surveillance approach to monitor the public health benefits of expanded HAART coverage [37,38]. 


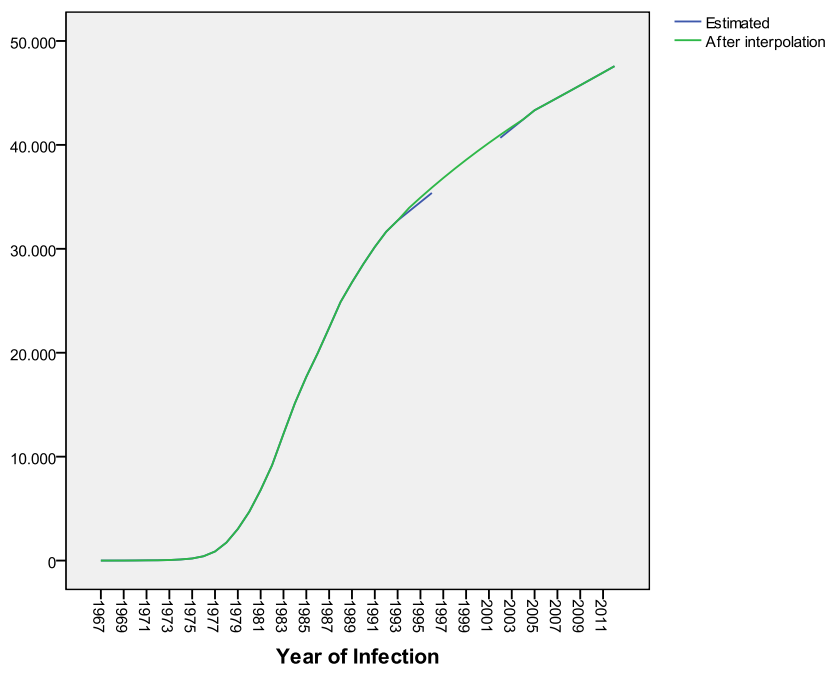

Figure 1: Estimated and Predicted HIV incidence after interpolation. Brazil, 1967-2012.

\begin{tabular}{|l|c|c|c|c|}
\hline \multicolumn{1}{|c|}{$\mathbf{t}$ (years) } & $\begin{array}{c}\text { Cumulative } \\
\text { distribution of } \\
\mathbf{t}(\%)\end{array}$ & $\begin{array}{c}\text { Year of HIV } \\
\text { infection }\end{array}$ & $\begin{array}{c}\text { HIV } \\
\text { incidence }\end{array}$ & $\begin{array}{c}\text { Number of } \\
\text { cases with no } \\
\text { CD4 count }\end{array}$ \\
\hline$<1$ & 31.6 & 2012 & 47573 & 16270 \\
\hline$\geq 1$ and $<2$ & 36.8 & 2011 & 46957 & 29677 \\
\hline$\geq 2$ and $<3$ & 42.0 & 2010 & 46346 & 26881 \\
\hline$\geq 3$ and $<4$ & 47.1 & 2009 & 45736 & 24194 \\
\hline$\geq 4$ and $<5$ & 52.2 & 2008 & 45130 & 21572 \\
\hline$\geq 5$ and $<6$ & 57.0 & 2007 & 44528 & 19147 \\
\hline$\geq 6$ and $<7$ & 61.5 & 2006 & 43927 & 16912 \\
\hline$\geq 7$ and $<8$ & 65.6 & 2005 & 43331 & 14906 \\
\hline$\geq 8$ and $<9$ & 69.3 & 2004 & 42450 & 13032 \\
\hline$\geq 9$ and $<10$ & 72.8 & 2003 & 41722 & 11348 \\
\hline$\geq 10$ and $<11$ & 76.1 & 2002 & 40970 & 9792 \\
\hline$\geq 11$ and $<12$ & 79.2 & 2001 & 40194 & 8360 \\
\hline$\geq 12$ and $<13$ & 82.2 & 2000 & 39392 & 7012 \\
\hline$\geq 13$ and $<14$ & 85.0 & 1999 & 38562 & 5784 \\
\hline$\geq 14$ and $<15$ & 87.6 & 1998 & 37703 & 4675 \\
\hline$\geq 15$ and $<16$ & 90.1 & 1997 & 36813 & 3644 \\
\hline$\geq 16$ and $<17$ & 92.4 & 1996 & 35890 & 2728 \\
\hline$\geq 17$ and $<18$ & 94.3 & 1995 & 34931 & 1991 \\
\hline$\geq 18$ and $<19$ & 95.8 & 1994 & 33934 & 1425 \\
\hline$\geq 19$ and $<20$ & 97.0 & 1993 & 32723 & 982 \\
\hline$\geq 20$ & 100.0 & 1992 & 31646 & 0 \\
\hline Total & & & & 240333 \\
\hline & & & & \\
\hline & & & & \\
\hline
\end{tabular}

Table 4: Cumulative distribution of time of HIV Infection to first CD4 count (t) and estimated number of undiagnosed HIV infected cases. Brazil, 2005-2012.

The methods applied in this study make maximal use of all available HIV surveillance data in Brazil to estimate trends in HIV incidence. The approach was based on a CD4 count depletion model and was able to trace the HIV incidence curve from 1967 to 2012. Past and recent estimates were fitted in a unique model. One of the advantages of our model for estimating HIV incidence is its ability to utilize the long history of HIV and AIDS surveillance data while adjusting for additional information on CD4 counts after 2002.

In order to have more precise tools to assess the impact of expanded antiretroviral therapy, other studies aimed to improve prevalence fitting and incidence trend estimation using different mathematical models [39-41] or incorporating data from incidence assays [42].

Despite of the incontestable impact of antiretroviral therapy on AIDS morbidity and mortality, in Brazil not much has been investigated about the proportion of people living with HIV/AIDS who are unaware of their serologic status and continue to spread the disease. In this study, we estimated that around 715,000 people live with HIV/AIDS in Brazil, from which one third do not have the first CD4 count, and is not benefiting from immediate treatment.

These results are similar to findings in other countries. In British Columbia, Canada, based on prevalence estimates, the proportion of unidentified HIV-positive individuals decreased from 49\%, in 1996, to $29 \%$, in 2011 [37]. In the USA, there were an estimated 1.2 million people living with HIV in $2008,80 \%$ of whom were estimated to have been diagnosed but only $77 \%$ of those were linked to care [42]. Among HIV infected youth, just $41 \%$ is aware of their diagnosis, while only $62 \%$ of those diagnosed engage medical care within 12 months of diagnosis [42].

Not only the delay in engagement in medical care favors the transmission of the virus by the patient but also the long latency period of the illness also hinders their treatment, since the response to therapy is worse in patients who initiate treatment with low CD4 count [43]. The results of this study showed that there are around 48,000 new infections a year in Brazil, for which only $32 \%$ have the first CD4 in the same year of HIV infection.

Many studies have pointed out the need of early detection of HIV $[44,45]$. The current technological advances allow through rapid tests to find in a few minutes the HIV status of an individual [46]. But, it is still necessary to promote HIV testing, especially among most-at-risk groups. Among 3859 men who have sex with men (MSM) recruited by RDS in 10 Brazilian cities, only $49 \%$ had ever tested for HIV. The overall HIV prevalence of HIV was $14.2 \%$ and half of those who tested HIV positive were not aware of their infection [21].

In Brazil, more than thirty years after the first AIDS case, the epidemic continues to spread. Limitations of prevention policies are shown in continued rates of new HIV infections. In fact, there are around 48,000 new infections a year in Brazil, or 25 per 100,000 populations. These rates have remained persistently high for the last decade, even with the extended coverage of HAART through the public health system. Development of new strategies to turn downward the incidence curve is currently a priority.

A growing number of studies have evidenced that wide and early initiation of antiretroviral therapy can reduce the level of HIV incidence in the population. It has been suggested that antiretroviral (ARV) drugs that have largely contributed to increase survival of PLWHA may also have an impact on HIV transmission not only at individual level but also at population level $[47,48]$.

The potential cumulative impact of early treatment of HIV-infected patients in reducing viral load and transmission rates has brought a new focus on the implementation of this strategy $[49,50]$. The benefits of treatment as prevention (TasP), however, largely depend on identifying undiagnosed individuals and ensuring linkage and retention in HIV care [51]. Considering that the Brazilian Ministry of Health has recently adopted the test-and-treat policy, the major challenge in Brazil is to stimulate periodic HIV testing, specifically targeting the most at risk populations.

Although the increasing coverage of HIV testing in Brazil gives 
some indication that people are generally open to routine HIV screening, as HIV testing in antenatal care for pregnant women, known benefits of early treatment are outweighed by a perceived burden related to stigma and fear of being positive [52-54]. The Brazilian Behavioral Surveillance Survey, 2012 found that more than $60 \%$ of those with self-evaluation of high HIV infection risk had never tested for HIV. As patients who belatedly starting therapy have lower survival, consume more resources, and reduce the chances of therapy success, policies to eliminate structural barriers to HIV testing are essential in Brazil.

\section{References}

1. Brookmeyer R, Gail MH (1994) AIDS Epidemiology: A Quantitative Approach. Oxford University Press, New York, USA.

2. Day NE, Gore SM, McGee MA, South M (1989) Predictions of the AIDS epidemic in the U.K.: the use of the back projection method. Philos Trans R Soc Lond B Biol Sci 325: 123-134.

3. Porter K, Johnson AM, Phillips AN, Darbyshire JH (1999) The practica significance of potential biases in estimates of the AIDS incubation period distribution in the UK register of HIV seroconverters. AIDS 13: 1943-1951.

4. Alioum A, Leroy V, Commenges D, Dabis F, Salamon R (1998) Effect of gender, age, transmission category, and antiretroviral therapy on the progression of human immunodeficiency virus infection using multistate Markov models. Groupe d'Epidémiologie Clinique du SIDA en Aquitaine Epidemiology 9: 605612.

5. Muñoz A, Xu J (1996) Models for the incubation of AIDS and variations according to age and period. Stat Med 15: 2459-2473.

6. Heisterkamp SH, de Vries R, Sprenger HG, Hubben GA, Postma MJ, et al. (2008) Estimation and prediction of the HIV-AIDS-epidemic under conditions of HAART using mixtures of incubation time distributions. Stat Med 27: 781-794.

7. Ades AE (1995) Serial HIV seroprevalence surveys: interpretation, design, and role in HIVIAIDS prediction. J Acquir Immune Defic Syndr Hum Retrovirol 9 490-499.

8. Szwarcwald $\mathrm{CL}$, Barbosa Júnior $A$, Souza-Júnior PR, Lemos KR, Frias PG, et al (2008) HIV testing during pregnancy: use of secondary data to estimate 2006 test coverage and prevalence in Brazil. Braz J Infect Dis 12: 167-172.

9. Wang N, Wang L, Wu Z, Guo W, Sun X, et al (2010) National Expert Group on HIVIAIDS Estimation: Estimating the number of people living with HIVIAIDS in China: 2003-09. Int J Epidemiol 39: ii21-ii28.

10. Montana LS, Mishra V, Hong R (2008) Comparison of HIV prevalence estimates from antenatal care surveillance and population-based surveys in sub-Saharan Africa. Sex Transm Infect 84: i78-78i84.

11. Fabiani M, Yoti Z, Nattabi B, Ayella EO, Opio AA, et al. (2007) Adjusting HIV prevalence data from a program for the prevention of mother-to-child transmission for surveillance purposes in Uganda. J Acquir Immune Defic Syndr 46: 328-331.

12. Kayibanda JF, Alary M, Bitera R, Kabeja A, Hinda R, et al. (2011) HIV Prevalence Comparison Between Antenatal Sentinel Surveillance and Demographic and Health Survey in Rwanda. Open AIDS J 5: 29-36.

13. Gonese E, Dzangare J, Gregson S, Jonga N, Mugurungi O, et al. (2010) Comparison of HIV prevalence estimates for Zimbabwe from antenatal clinic surveillance (2006) and the 2005-06 Zimbabwe Demographic and Health Survey. PLoS One 5: e13819.

14. Barcellos C, Bastos FI (1996) [Social networks and diffusion of AIDS in Brazil]. Bol Oficina Sanit Panam 121: 11-24

15. Landmann Szwarcwald C, Bastos FI, de Castilho EA (1998) The Dynamics of the AIDS Epidemic in Brazil: A Space-Time Analysis in the Period 1987-1995. Braz J Infect Dis 2: 175-186.

16. Brito AM, Castilho EA, Szwarcwald CL (2001) [AIDS and HIV infection in Brazil: a multifaceted epidemic]. Rev Soc Bras Med Trop 34: 207-217.

17. Barbosa Júnior A, Szwarcwald CL, Pascom AR, Souza Júnior PB (2009) [Trends in the AIDS epidemic in groups at highest risk in Brazil, 1980-2004]. Cad Saude Publica 25: 727-737.

18. Souza Júnior PR, Szwarcwald CL, Barbosa Júnior A, Carvalho MF, Castilho EA (2004) [HIV infection during pregnancy: the Sentinel Surveillance Project, Brazil, 2002]. Rev Saude Publica 38: 764-772.
19. Szwarcwald CL, de Carvalho MF, Barbosa Júnior A, Barreira D, Speranza FA, et al. (2005) Temporal trends of HIV-related risk behavior among Brazilian military conscripts, 1997-2002. Clinics (Sao Paulo) 60: 367-374.

20. Szwarcwald $C L$, de Souza Júnior $P R$, Damacena $G N$, Junior $A B$, Kendall $C$ (2011) Analysis of data collected by RDS among sex workers in 10 Brazilian cities, 2009: estimation of the prevalence of HIV, variance, and design effect. J Acquir Immune Defic Syndr 57: S129-135.

21. Kerr LR, Mota RS, Kendall C, Pinho Ade A, Mello MB, et al. (2013) HIV among MSM in a large middle-income country. AIDS 27: 427-435.

22. Guibu IA, Barros MB, Donalísio MR, Tayra Â, Alves MC (2011) Survival of AIDS patients in the Southeast and South of Brazil: analysis of the 1998-1999 cohort. Cad Saude Publica 27: S79-92.

23. Van Sighem Al, Gras LA, Reiss P, Brinkman K, de Wolf F, et al. (2010) Life expectancy of recently diagnosed asymptomatic HIV-infected patients approaches that of uninfected individuals. AIDS 24: 1527-1535.

24. Rehle T, Shisana O, Pillay V, Zuma K, Puren A, et al. (2007) National HIV incidence measures--new insights into the South African epidemic. S Afr Med J 97: 194-199.

25. Ndawinz JD, Costagliola D, Supervie V (2011) New method for estimating HIV incidence and time from infection to diagnosis using HIV surveillance data: results for France. AIDS 25: 1905-1913.

26. Bätzing-Feigenbaum J, Loschen S, Gohlke-Micknis S, Zimmermann R, Herrmann A, et al. (2008) Country-wide HIV incidence study complementing HIV surveillance in Germany. Euro Surveill 13: pii18971.

27. Hall HI, Song R, Rhodes P, Prejean J, An Q, et al. (2008) Estimation of HIV incidence in the United States. JAMA 300: 520-529.

28. Committee on Review Data Systems for Monitoring HIV Care, Institute of Medicine (2012) In: Ford MA, Spicer CM (eds) Monitoring HIV Care in the United States: Indicators and Data Systems. National Academies Press, Washington.

29. Camargo KR Jr, Coeli CM (2000) [Reclink: an application for database linkage implementing the probabilistic record linkage method]. Cad Saude Publica 16: 439-447.

30. Lodi S, Phillips A, Touloumi G, Geskus R, Meyer L, et al. (2011) Time from human immunodeficiency virus seroconversion to reaching CD4+ cell count thresholds $<200,<350$, and $<500$ cells $/ \mathrm{mm}^{3}$ : assessment of need following changes in treatment guidelines. Clin Infect Dis 53: 817-825.

31. Instituto Brasileiro de Geografia e Estatística (IBGE), Pesquisa Nacional por Amostra de Domicílios (2010) Um Panorama da saúde no Brasil: acesso e utilização dos serviços, condições de saúde e fatores de risco de proteção à saúde 2008 .

32. Fazito E, Cuchi P, Fat DM, Ghys PD, Pereira MG, et al. (2012) Identifying and quantifying misclassified and under-reported AIDS deaths in Brazil: a retrospective analysis from 1985 to 2009 . Sex Transm Infect 88: i86-94.

33. Marins JR, Jamal LF, Chen SY, Barros MB, Hudes ES, et al. (2003) Dramatic improvement in survival among adult Brazilian AIDS patients. AIDS 17: 16751682.

34. Matida LH, Ramos Jr AN, Moncau JE, Marcopito LF, Marques HH, et al. (2007) AIDS by mother-to-child transmission: survival analysis of cases followed from 1983 to 2002 in different regions of Brazil. Cad Saude Publica. 23: S435-44.

35. Grinsztejn B, Hosseinipour MC, Ribaudo HJ, Swindells S, Eron J, et al. (2014) Effects of early versus delayed initiation of antiretroviral treatment on clinical outcomes of HIV-1 infection: results from the phase 3 HPTN 052 randomised controlled trial. Lancet Infect Dis 14: 281-290.

36. Kilmarx PH, Mutasa-Apollo T (2013) Patching a leaky pipe: the cascade of HIV care. Curr Opin HIV AIDS 8: 59-64.

37. Nosyk B, Montaner JS, Colley G, Lima VD, Chan K, et al. (2014) The cascade of HIV care in British Columbia, Canada, 1996-2011: a population-based retrospective cohort study. Lancet Infect Dis 14: 40-49.

38. Pokrovskaya A, Popova A, Ladnaya N, Yurin O (2014) The cascade of HIV care in Russia, 2011-2013. J Int AIDS Soc 17: 19506.

39. Vesga JF, Cori A, van Sighem A, Hallett TB (2014) Estimating HIV incidence from case-report data: method and an application in Colombia. AIDS 28: S489496. 
Citation: Szwarcwald CL, Pascom ARP, de Souza Júnior PR (2015) Estimation of the HIV Incidence and of the Number of People Living With HIVIAIDS in Brazil, 2012. J AIDS Clin Res 6: 430. doi:10.4172/2155-6113.1000430

40. Brown T, Bao L, Eaton JW, Hogan DR, Mahy M, et al. (2014) Improvements in prevalence trend fitting and incidence estimation in EPP 2013. AIDS 28: S415425 .

41. Murray CJ, Ortblad KF, Guinovart C, Lim SS, Wolock TM, et al. (2014) Global, regional, and national incidence and mortality for HIV, tuberculosis, and malaria during 1990-2013: a systematic analysis for the Global Burden of Disease Study 2013. Lancet 384: 1005-1070.

42. Bao L, Ye J, Hallett TB (2014) Incorporating incidence information within the UNAIDS Estimation and Projection Package framework: a study based on simulated incidence assay data. AIDS 28: S515-522.

43. Gardner EM, McLees MP, Steiner JF, Del Rio C, Burman WJ (2011) The spectrum of engagement in HIV care and its relevance to test-and-treat strategies for prevention of HIV infection. Clin Infect Dis 52: 793-800.

44. Zanoni BC, Mayer KH (2014) The adolescent and young adult HIV cascade of care in the United States: exaggerated health disparities. AIDS Patient Care STDS 28: 128-135

45. Luz PM, Grinsztejn B, Velasque L, Pacheco AG, Veloso VG, et al. (2014) Longterm CD4+ cell count in response to combination antiretroviral therapy. PLoS One 9: e93039.

46. Dilernia DA, Monaco DC, Cesar C, Krolewiecki AJ, Friedman SR, et al. (2013) Estimation of HIV-testing rates to maximize early diagnosis-derived benefits a the individual and population level. PLoS One 8: e53193.

47. Smith MK, Rutstein SE, Powers KA, Fidler S, Miller WC, et al. (2013) The detection and management of early HIV infection: a clinical and public health emergency. J Acquir Immune Defic Syndr 63: S187-199.
48. da Motta LR, Vanni AC, Kato SK, Borges LG, Sperhacke RD, et al. (2013) HIV Rapid Test Evaluation Group. Evaluation of five simple rapid HIV assays for potential use in the Brazilian national HIV testing algorithm. J Virol Methods 194: 132-137.

49. Montaner JS, Lima VD, Harrigan PR, Lourenço L, Yip B et al. (2014) Expansion of HAART coverage is associated with sustained decreases in HIVIAIDS morbidity, mortality and HIV transmission: the "HIV Treatment as Prevention" experience in a Canadian setting. PLoS One 9: e87872.

50. Tanser F, Bärnighausen T, Grapsa E, Zaidi J, Newell ML (2013) High coverage of ART associated with decline in risk of HIV acquisition in rural KwaZulu-Natal, South Africa. Science 339: 966-971.

51. Lo YR, Kato M, Phanuphak N, Fujita M, Duc DB, et al. (2014) Challenges and potential barriers to the uptake of antiretroviral-based prevention in Asia and the Pacific region. Sex Health 11: 126-136.

52. Wilson D, Taaffe J, Fraser-Hurt N, Gorgens M (2014) The economics, financing and implementation of HIV treatment as prevention: what will it take to get there? Afr J AIDS Res 13: 109-119.

53. Golub SA, Gamarel KE (2013) The impact of anticipated HIV stigma on delays in HIV testing behaviours: findings from a community-based sample of men who have sex with men and transgender women in New York City. AIDS Patient Care STDS 27: 621-627.

54. Wei C, Yan H, Yang C, Raymond HF, Li J, et al. (2014) Accessing HIV testing and treatment among men who have sex with men in China: a qualitative study. AIDS Care 26: 372-378. 